\title{
Almanca Öğretiminde İngilizcenin Köprü Dil Olarak Kullanılması
}

\author{
Lokman Tanrıkulu (D), Nevşehir - Tolga Bayter (D), Nevşehir
}

https://dx.doi.org/10.37583/diyalog.802207

$\ddot{O}_{z}$

Küreselleşen dünya göz önüne alındığında ortak dilin İngilizce olduğu görünmektedir. Bütün dünyada olduğu gibi ülkemizde de birinci yabancı dil olarak İngilizce öncelik kazanmıştır. Almanca, Fransızca, Rusça gibi diller ikinci yabancı dil olarak değerlendirilmiştir. Sanayi ülkesi olan Almanya'nın ekonomisinden aldığı güçle, dilini diğer ülkelere kabul ettirdiğini göz ardı etmemek gerekir. Bunun dışında Avrupa'da en çok konuşulan Anadili olma özelliği de Almancanın önemini arttırmıştır. Söz konusu özelliklerinden dolayı Almanca ikinci yabancı dil öğrenme sıralamasında üst sıralarda yer almaktadır. İkinci yabancı dili öğrenen bir öğrenci için birinci yabancı dil her zaman yardımcı dil görevi görmektedir. Öğrenci birinci yabanc1 dili öğrenirken edindiği tecrübeyi, belirlediği stratejiyi, ikinci yabancı dil için de kullanmaktan kaçınmamalıdır. Birinci yabancı dil olarak İngilizce öğrenen bir öğrenci, ikinci yabancı dil olarak Almancayı seçtiğinde, bu tecrübe ve stratejilerini kolaylıkla kullanabileceği bir ortamı yakalamış olmaktadır. Bunun sebebi ise Almanca ve İngilizcenin birçok ortak noktaya sahip olmasıdır. Ülkemizde bu önemli iki dili öğreten ve öğrenen kişinin fazla olması, bu çalışmayı yapmamızı teşvik etmiştir. Bu çalışmada doküman inceleme (analizi) yöntemi kullanılarak ikinci yabancı dil olarak Almanca dili eğitiminde birinci yabancı dil olan İngilizcenin köprü dil olarak kullanılıp, daha kolay bir şekilde öğrenilmesi ve anlaşılması incelenmiştir.

Anahtar Sözcükler: Almanca, Ingilizce, köprü dil, yabancı dil.

\begin{abstract}
Using English as a bridge in teaching German

In view of the globalizing world, English seems to be the lingua franca. As it is in the whole world, in our country as well, English gains the priority as the first foreign language. The languages such as German, French and Russian are considered to be secondary foreign languages. Apart from this, being the most widely spoken mother tongue throughout Europe, it increases the importance of German. Due to these properties, German is at the top as a second foreign language. For the learner of a second foreign language, the first foreign language always serves as a facilitator in learning the second foreign language. The learner should not avoid deploying the same experience gained, the same strategy s/he picked up during the first foreign language learning process when learning the second foreign language. When a learner who learned English as the first foreign language prefers to learn German as the second foreign language, s/he owns the environment where s/he can use the previous experiences and strategies without any difficulty. This is because German and English have so many common points. Document review method is used in this study. The fact that there are a number of great learners and teachers of these two leading languages has motivated us to conduct this study. Our study examines how English, the first
\end{abstract}

Einsendedatum: 24.03.2020

Freigabe zur Veröffentlichung: 30.09.2020 
foreign language, functions as a bridge in teaching German as the second foreign language and how it is learned and comprehended more easily.

Keywords: German, English, bridge language, foreign language. 


\section{EXTENDED ABSTRACT}

Learning a different foreign language becomes more essential day by day parallel to our developing world. Language, being a living communication system as well, improves itself day after day. At such a time, learning a new language or a second foreign language also becomes more crucial in our modern life. Especially recently, the investment in foreign language teaching in our country has been on a far better increase. People do not suffice with only one foreign language anymore but they have started to learn a second and even a third foreign language.

In our country, English in general is being taught as the first and German as the second foreign language. Teaching German as a second foreign language is not limited with our country. In many countries English is the first foreign language that comes to the mind due to its global power, and then, German because it is the language of economy and industry, as well as, it is a cognate language as we mentioned above. Using Turkish in teaching German is much more difficult than using English because there is a very few relationship between Turkish and German. Therefore, structural difference, grammar pattern, phonetics etc. limits Turkish in this sense, and accordingly, they makes it difficult for the students during their learning process.

Where German and English are the two members of the Germanic group of the Indo-European Language Family, Turkish belongs to the Ural-Altaic language family. These two language families have rather different structures. It is quite normal that one experiences difficulties while learning languages of different language families. However, the learner will gain a certain experience on the first try. Thus, when the learner faces with similar difficulties for the second time, they will use their previous experience for the second language and it will take less time and effort. Today, teaching of English in schools starts relatively earlier than German, so the learner can learn acquire German faster and more easily. This happens with the advantage of English as the learner uses English as a bridge to the second foreign language. German and English possess structural characteristics different from Turkish. When analysing such differences, the principle of induction has been adopted in our study.

Even though German and English belong to the same group of the same language family, there are still some dissimilarities. We can call it like two brothers, who looking alike physically but with different characters. We could give the verb inflection as the first example to this. In German just like in Turkish, a single inflectional morpheme is donated to each subject, which is not the case in English. In English, we use only in Present Simple, the third person singular has an inflectional morpheme. In addition, in German the formal personal pronoun "Sie" is distinguished in writing by capitalization wherever it takes place in the sentence. In English, there is no such extra pronoun for politeness like "Sie". This politeness is expressed by "you" in English.

German has six tenses, but English has twelve basic tenses; four Past, four Present, four Future. Where the same sentence pattern is used for present continuous and simple present in German, this is not the case in English. In English the two tenses are used within their own rules. 
As we mentioned above, both languages possess articles. However, articles in English are either definite or indefinite and they come before the objects precede nouns, but there are zero articles, most commonly, in proper nouns, mass nouns and/ or countable plural nouns. They are never capitalized unless they come at the beginning of a sentence. On the contrary, German has articles for almost all nouns (except the proper nouns). The nouns with articles are always written in capital letters like proper nouns wherever they are as in Turkish. In German the first letter of articles are capitalized if they come at the beginning of a sentence. Additionally, articles in German display objective, accusative, dative cases of nouns due to its structure but in English prepositions are used for these situations.

As for the degrees of adjectives in German, adjectives come between the article and the noun. It is highly important whether the article is definite or indefinite, singular or plural, subject to a change or not, which is not the case in English, either.

Conjunctions have a significant place in both cognate languages as in every language. In English, connectives do not affect the sentence order but in German they do. In German, the position of the verb changes may vary according to the conjunctions used. There are three types of conjunction groups in German. The first type of conjunctions connects the two main sentences and the verbs do not change their place. In the second type of conjunctions, a main sentence and a clause are interconnected, and the verb of the clause goes to the end of the sentence because of the conjunction. The third type of conjunctions connects a main sentence with the clause, but this time the verb is located just behind the conjunction due to the conjunction. However in English the verb takes the second place in both main and clause sentences.

In this study, we have tried to show where and how English (L2) can be used as a bridge language in teaching German (L3) as a second foreign language. It is quite obvious that English, the first foreign language (L2), will contribute in learning German as the second foreign language (L3) since they both come from the same language family and also the same group and have certain linguistic properties in common.

The teacher prepares teaching material which meets these two languages on a common ground while teaching German as a second foreign and thus enables the student to use their previously learned English grammar, vocabulary through German, which will increase the learning output in this direction because the student feels more confident and adapts to German learning much more easily owing to the knowledge of another foreign language that is English.

In this study, we have used a document review (analysis) method and studied on learning and comprehending German more easily by using English as a bridge language. 


\section{Giriş}

Kültürün unsurlarından olan dil; insanların birbiriyle doğrudan iletişim kurabilmeleri için başvurdukları sözlü ve yazılı bir araçtır (Şavlı - Kalafat 2014: 1368). Boeckman, kişinin ilk edindiği anadili (Muttersprache) L1 olarak birinci yabancı dil, öğrenilen ikinci dili (Zweitsprache) L2 olarak, öğrenilen üçüncü dili (Drittsprache / Tertiärsprache) L3 olarak gruplara ayırmıştır (2010: 6).

Gelişmekte olan dünya ile birlikte farklı bir yabancı dil öğrenimi, önemini gün geçtikçe daha çok hissettirmektedir. Aynı zamanda dil yaşayan bir varlık olduğu için günden güne kendini geliştirmektedir. Böyle bir ortamda yeni dil veya ikinci yabancı dili öğrenmek de çağdaş yaşamda önemini fazlasıyla arttırmaktadır. İtalyanların dediği gibi "her bir dil, yeni bir penceredir. İnsanlar sürekli yeni pencerelerden bakmalı ve kendilerini geliştirmelidir." Bizim kültürümüzde de bu söze benzer bir atasözü şöyle der: "Bir dil bir insan, iki dil iki insandır." Farklı toplumlar ve kültürler de olsak bu atasözleriyle dil öğreniminin ne kadar önemli olduğu ortaya koyulmuştur.

Özellikle son dönemlerde ülkemizde dile yapılan yatırım gittikçe artmaktadır. Artık insanlar bir dil ile yetinmeyip ikinci hatta üçüncü yabancı dili de öğrenmeye başlamıştır. Milli Eğitim Bakanlığı ise bu konuda ekstra çalışmalar yürütmektedir. Örneğin daha önce çocukların yabancı dil ile tanışması ilkokul dördüncü sınıfta gerçekleşiyordu. 2013-2014 eğitim-öğretim yılından itibaren ikinci yabancı dilin öğretilmesi ilkokul ikinci sınıfa kadar indirilmiştir (Müfredat, 2013).

Özel okullarda ise durum çok daha farklıdır. Bazı özel okullar, okul öncesi döneminde, anaokulunda çift öğretmenli bir sistem uygulamaktadır. Çift öğretmenli sistem, bir anadilinde öğretmenin olduğu ve bir de özel okulun öğretmek istediği hedef dilin (İngilizce, Almanca, Rusça, Fransızca vs.) öğretmeninin bulunduğu bir eğitim modelidir. Böyle bir eğitim ortamında çocuk/öğrenci hedef dildeki öğretmeni ile kesinlikle anadilinde iletişim kuramaz. Hedef dildeki öğretmen, öğrencinin anadilini anlıyor olsa bile tepki vermez. Burada amaç öğrenciye hedef dili daha sık kullandırmaktır. Öğretmen hedef dili bir şekilde kullanması için öğrenciyi teşvik eder ve hedef dil kullanıldığında iletişime geçileceğini kesin bir şekilde öğrencisine öğretmiş olur. Böylelikle öğrenci/çocuk hedef dili kullanmak zorunda kalarak dili öğrenmeye başlar.

$\mathrm{Bu}$ evre atlatılıp hedef dil öğretildikten sonra artık dil öğretimi çeşitlendirilmeye başlanır. Öğrenci/çocuk anadilinin yanında birinci yabancı dile sahip olur ve ikinci yabancı dili öğrenmeye hazır hale getirilir. İkinci yabancı dil öğretilme evresinde ise, öğrenciye ders anadili yerine ilk öğrenilen yabancı dil ile bir köprü kurularak anlatılır ve böylece öğrencinin hem birinci yabancı dili pekiştirilmiş hem de ikinci yabancı dil öğretimi daha kolay bir süreç olarak gerçekleştirilmiş olur. Kolay gerçekleşmesinin sebebi ise birinci yabancı dil ile ikinci yabancı dil arasında yapısal bir benzerlik olmasıdır. Bu yapısal benzerliğe en güzel örnek olarak Almancayı ve İngilizceyi verebiliriz. Almanca ve İngilizce aynı dil ailesinden, Hint- Avrupa Dil ailesinin, Avrupa kolunun, Germen dillerinin dört üyesinden ikisidir (Akar 2005: 16-17). Hem aynı aile, hem de aynı koldan olmaları sebebiyle, dil bilgisi, kelime, tonlama gibi çok fazla ortak 
yöne sahiptirler. Bu yüzden hangi dili ikinci yabancı dil olarak seçeceksek diğer dili köprü dil olarak kullanmak bize çok yardımcı olacaktır.

Ülkemizde genelde İngilizcenin ardından ikinci dil olarak Almanca öğretilmektedir. Öğretilen ikinci dilin Almanca olması yalnızca bizim ülkemize has bir özellik değildir. Dünya üzerindeki birçok ülkede yabancı dil denildiğinde ilk olarak akla küresel gücünden dolayı İngilizce gelmektedir. Daha sonra hem ekonomi ve sanayi dili olması, hem de yukarıda bahsettiğimiz gibi akraba dil olmasından dolayı Almanca gelmektedir (Küzeci 2015: 17).

Almanca öğretiminde Türkçeyi kullanmak İngilizceyi kullanmaktan zordur. Çünkü Türkçe ile Almanca arasında herhangi bir dil akrabalığı yoktur. Bu yüzden de yapısal farklılığın, dil bilgisel düzenin, fonetiğin vs. Türkçeyi bu konuda kısıtlaması bu süreçte öğrencileri oldukça zorlamaktadır. Bu iki dilin belki de tek ortak yönlerinin her bir özne için fiil çekimi olduğu söylenebilir. İki dilin de ne kadar zengin birer dil olduğu düşünülürse bunun çölde bir kum tanesi kadar ufak bir benzerlik olduğu görülebilir. Bu sebepten dolayı ikinci yabancı dil Almanca (L3) için birinci yabancı dil İngilizcenin (L2) köprü dil olarak kullanılabilmesini doküman incelemesi (analizi) yöntemini kullanarak incelemeye çalıştık. Araştırma kapsamında incelenen konuyla ilgili olgu ve olaylar hakkında bilgi içeren yazılı belgelerin analiz edilmesiyle veri sağlanmasına doküman incelemesi denilmektedir (Karataş 2015: 11). Araştırma yapılan alanla ilgili pek çok bilgi görüşme ve gözlem yapmaya gerek kalmaksızın belge inceleme yoluyla elde edilebilir. Bu sayede araştırmacı zaman ve kaynak tasarrufu sağlamış olur. Hangi dokümanın önemli olduğu ve veri kaynağı olarak kullanılabileceğine araştırma konusuna bakarak karar vermek gerekir (Yıldırım-Şimşek 2008: 188).

\section{Almanca Öğretiminde İngilizcenin Köprü Dil Olarak Kullanılabileceği Önemli Yapılar}

Yukarıda da belirtildiği gibi Almanca ve İngilizce Hint-Avrupa dil ailesinin Germen kolunun iki üyesiyken, Türkçe ise Ural-Altay dil ailesine aittir. Bu iki dil ailesi birbirinden oldukça farklı yapılara sahiptir. Farklı dil ailelerine mensup dilleri öğrenirken kişinin zorluklar yaşaması gayet normaldir. Ama kişi bu zorlukları ilk seferde yaşadığında belli bir tecrübe edinecektir. Dolayısıyla ikince kez aynı zorluklarla karşılaştığında, ilk dil öğreniminden elde ettiği tecrübeyi ikinci dil için kullanacağından öğrenimi zaman açısından daha kısa sürede ve daha kolay olacaktır. Günümüzde de İngilizce öğrenimi Almancaya nazaran daha erken yaşlarda başladığı için, öğrenci İngilizce öğrenimindeki tecrübeyi Almanca öğrenimi için kullanarak, dil öğrenimini daha kısa ve hızlı bir şekilde yapabilir. Bu da İngilizcenin burada köprü dil olarak kullanılmasıyla gerçekleşir. Almanca ve İngilizcenin Türkçeden farklı yapısal özellikleri mevcuttur. Bu yapısal farklılıkları incelerken tümevarım ilkesi göz önüne alınarak anlatılmak istenmiştir. Başlangıç seviyesi A1.1 için bazı yapısal farklılıklar şunlardır: 
- Alfabe: Almanca (L3) ve İngilizce (L2)nin kullandığı alfabe ile Türkçe L1'in kullandığı alfabe arasında da farklar bulunmaktadır. Türkçe yirmi dokuz harften, sekiz sesli, yirmi bir sessiz harften oluşmaktadır ama İngilizce (L2) ve Almanca (L3)da özel harfler dışında yirmi altı harf vardır. Türkçe (L1)de büyük $I$ harfi varken İngilizce (L2) ve Almanca (L3)de büyük $\dot{I}$ yoktur ve bunun yerine büyük I kullanılmaktadır.

- Ụ̣̈üncü Tekil Kişi ve İyelik Eki: Türkçede üçüncü tekil kişi sadece "o" kişisi ile kullanılırken, Almancada ve İngilizcede işin içine cinsiyet ayırımı girdiği için farklı kelimeler kullanılmaktadır. Almanca için er, sie, es. İngilizce içinse he, she, it, kullanılır. Er ve he, erkekler için, sie ve she, kadınlar için kullanım bulurken, es ve it, neutral öznelerin yerine geçen zamirler olarak karşımıza çıkmaktadır.

$\begin{array}{lccr}\text { Almanca L3: } & \mathbf{E r / S i e / \text { Es }} & \text { spielt } & \text { Fußball. } \\ \text { İngilizce L2: } & \text { He/ She/ It } & \text { plays } & \text { football. } \\ \text { Türkçe L1: } & \text { O } & \text { futbol } & \text { oynar. }\end{array}$

Burada sadece üçüncü tekil kişinin farklılığından bahsedilmemeli, aynı zamanda üçüncü tekil kişinin iyelik ekinden de bahsedilmelidir çünkü yukarıdaki Almanca (L3), İngilizce (L2) benzerliği ve Türkçe (L1) farklılığı iyelik ekinde de devam etmektedir (Arak 2010: 56).

Almanca L3: Das ist sein Ball. / Das ist ihr Ball.

İngilizce L2: This is his ball. / This is her ball.

Türkçe L1: $\quad$ Bu onun topu. / Bu onun topu.

Örneklerde de görüldüğü gibi Almanca (L3) ve İngilizce (L2)de iyelik ekleri cinsiyetleri belli ederken, Türkçe (L1)de böyle bir şey söz konusu değildir. L1deki cinsiyeti anlamak için bu cümleden önceki cümlelere bakıp, bahsedilen kişinin cinsiyeti bulunmalıdır. Örneğin; Ali bugün okula gelmedi ama onun topu burada. Bu örnekte olduğu gibi, sadece ikinci cümleyi okuyarak ya da söyleyerek herhangi bir cinsiyete ulaşamayız. Bu yüzden bir önceki cümleye bakarak cinsiyete ulaşabiliriz.

- Ekler: Türkçe bulunmuş olduğu dil ailesi itibari ile sondan eklemeli bir dil olduğu için, Almanca ve İngilizceye göre daha farklı bir yapıya sahiptir. Kelime kullanımı açısından daha ekonomik bir dil özelliğini taşımaktadır.

Almanca L3: Ich bin zu Hause.

İngilizce L2: I am at home.

Türkçe L1: Evdeyim.

Örneklerde de görüldüğü gibi Türkçe'de (L1) bir kelime ile ifade edilen cümle, Almanca (L3) ve İngilizce'de (L2) dört kelime ile ifade edilmektedir. Türkçe'de (L1) kişi zamiri, zaman eki kelimeye sondan eklenmiş durumdayken, Almanca (L3) ve İngilizce'de (L2) bu ekler için ayrı ayrı kelimeler kullanılmıştır. 
- İsimlerde Tanımlık: Birinci yabancı dil İngilizce (L2) ve ikinci yabancı dil Almanca (L3) bulundukları dil ailesi bakımından nesne isimlerinde bir tanımlığa sahiptirler. Özellikle Almancada (L3) her ismin bir tanımlı̆̆ (Artikeli) vardır. Almancada (L3) herhangi bir adın bu tanımlık ile öğrenilmesi şarttır çünkü tanımlık, ismin cinsiyetini, tekil ya da çoğul olmasını, çekim şekli gibi durumları belirtir (Zengin 2016: 26). Ama İngilizce (L2) için bu koşullar geçerli değildir. Tanımlık belirli ve belirsiz olmak üzere ikiye ayrılır. Eğer bir nesneden ilk defa bahsediliyorsa belirsiz tanımlığı kullanılır. Bu nesneden ikinci kez bahsedilirken de belirli tanımlığ kullanılır. Ama Türkçe (L1) için böyle bir şey söz konusu değildir. Almanca (L3) için belirsiz tanımlık; ein, eine ve ein'dır. İngilizce (L2) içinse $a$ ve $a n$ 'dir. Belirli tanımlık ise, Almanca (L3) için der (maskulin), die (feminin), das (neutral) ve çoğul isimler için yine die (plural)'dir. İngilizce (L2)de ise sadece the'dir.

$\begin{array}{rrrrr}\text { Belirsiz Tanımlık: } & \text { Almanca L3: } & \text { ein Apfel, } & \text { eine Schere, } & \text { ein Buch } \\ & \text { İngilizce L2: } & \text { an appel, } & \text { a scissors, } & \text { a book } \\ \text { Türkçe L1: } & \text { bir elma, } & \text { bir makas, } & \text { bir kitap }\end{array}$

Örneklerde de görüldüğü gibi Türkçe (L1), İngilizce (L2), Almanca (L3) için belirsiz tanımlıkta çoğul isim kullanılmamaktadır ki bu da bu üç dilin nadir ortak özelliklerinden biridir.

Belirli Tanımlık:

$\begin{array}{llll}\text { Almanca L3: der Apfel, } & \text { die Schere, } & \text { das Buch } & \text { die Bücher } \\ \text { İngilizce L2: the apple, } & \text { the scissors, } & \text { the book } & \text { the books } \\ \text { Türkçe L1: elma, } & \text { makas, } & \text { kitap, } & \text { kitaplar }\end{array}$

Örneklerde de görüldüğü gibi Almanca (L3) ve İngilizcede (L2) belirli tanımlıkta artikel kullanılıyorken, Türkçede (L1) herhangi bir belirtece ihtiyaç duyulmamaktadır.

- Cümledeki ögelerin dizilişleri: Almanca ve İngilizcede cümle dizilişleri özne + yüklem + nesne'şeklindedir. Yani $\mathbf{S}+\mathbf{V}+\mathbf{O}$ ' dur Türkçede ise bu diziliş özne + nesne + yüklem 'şeklinde kendini göstermektedir.. Yani S+O+V'dir (Arak 2010: 52).

Almanca L3: Ich esse Brot.

İngilizce L2: I eat bread.

Türkçe L1: Ben ekmek yerim.

- Soru Cümleleri: Soru cümleleri, ele aldığımız üç dil için; "Evet - Hayır Türkçe (L1)", "Yes - No İngilizce (L2)", "Ja- Nein Almanca (L3)", ya da "beş N bir K Türkçe (L1), "W-Question İngilizce (L2)", "W-Fragen Almanca (L3) olarak iki 
gruba ayrılır. Türkçe (L1) için "Evet- Hayır" soru cümlelerinde " $m i$ ya da $m \imath$ ?" soru eki en sonda kullanırken İngilizce (L2) ve Almanca (L3) için fiilin kendisi cümlenin en başında kullanılmaktadır.

Almanca L3: Bist du müde?

İngilizce L2: Are you tired?

Türkçe L1: Yorgun musun?

$\mathrm{Bu}$ sorulara verilen cevapları "olumlu ve olumsuz" olarak iki ayrı durumda da incelememiz gerekmektedir.

Olumlu; $\quad$ Almanca L3: Ja, ich bin müde.

İngilizce L2: Yes, I am tired.

Türkçe L1: Evet, yorgunum.

Örneklerde de görüldüğü gibi, olumlu cevaplarda Almanca (L3) ve İngilizce (L2) için cümle dizilişi onaylama kelimesi + özne + olmak fiili + slfat şeklindeyken, Türkçe (L1) için onaylama kelimesi + sıfata eklenmiş iyelik eki olarak gerçekleşmiştir.

Olumsuz; Almanca L3: Nein, ich bin nicht müde.

İngilizce L2: No, I am not tired.

Türkçe L1: Hayır, yorgun değilim.

Örneklerde de görüldüğü gibi, olumsuz cevaplarda Almanca (L3) ve İngilizce (L2) için cümle dizilimi onaylamama kelimesi + özne + olmak fiili + olumsuzluk kelimesi + sıfat olarak sıralanırken, Türkçe (L1) için ise aynı durum, onaylamama kelimesi + sıfat + olumsuzluk kelimesine eklemiş iyelik eki olarak gerçekleşmiştir.

Türkçe (L1) için "beş N bir K” “Ne? Neden? Nasıl? Ne zaman? Nerede? Kim?" şeklinde ifade edilirken, İngilizce (L2) için what, where, when, which, why, who (Questions, 2019) ve Almanca (L3) için wer, was, warum, wo, woher, wohin kelimeleri kullanılmaktadır (Zengin, 2016, s 129).

Almanca L3: Wo bist du?

İngilizce L2: Whereare you?

Türkçe L1: $\quad$ Neredesin?

Örneklerde de görüldüğü gibi, soru cümlesi Almanca (L3) W-Fragen ve İngilizce (L2)de W-Question'dan sonra, olmak fiili + özne ile oluşturuluyorken, Türkçe (L1) de ise "beş N" 'den biri iyelik ekiyle birleşerek soru oluşumunu sağlamaktadır.

- Sıfatların Derecelendirilmesi: Bir varlı̆̆ın ya da bir nesnenin etkili bir şekilde anlatılmasını, özelliklerinin belirtilmesini sağlayan kelimelere sıfat denir. Sıfatlar, derecelendirmek için de kullanılır. Derecelendirme üç şekilde yapılır. Yalın hali, üstünlük hali ve en üstünlük halidir. Türkçede (L1) derecelendirme sıfatın yalın hali / daha / en olarak, Almanca L3 için der Positiv / der Komparativ -er / der Superlativ -st olarak, L2 için eğer sıfat tek heceli ise 
comperatives -er / Superlatives the -est, eğer birden fazla heceli ise comperatives more/ superlatives the most olarak teşkil edilmektedir.

\begin{tabular}{cccc} 
& Der Positiv & Der Komparativ & Der Superlativ \\
\cline { 2 - 3 } Almanca L3: & schön & schöner & schönst \\
& billig & billiger & billigst \\
& Pozitiv & Competatives & Superlatives \\
\cline { 2 - 4 } İngilizce L2: & beautiful & more beautiful & the most beautiful \\
& cheap & cheaper & the cheapest \\
& Yalın hali & Daha hali & En Hali \\
Türkçe L1: & güzel & daha güzel & en güzel \\
& ucuz & daha ucuz & en ucuz
\end{tabular}

Yukarıda verilen konu başlıkları detaylı bir şekilde incelendiği takdirde Anadili Türkçe (L1) olan biri, birinci yabancı dil olarak İngilizce (L2) öğrendiğinde belli başlı farklılıklarla karşılaştığı görülmektedir. Örneğin alfabe, ekler, cümle yapısı, sıfat vb. Bu farklılıklara uyum sağladığında ise ikinci yabancı dil olarak Almanca (L3) öğreniminde artık Anadiline göre farklılık gösteren konular İngilizcenin köprü dil olarak kullanımı sayesinde benzerliklere dönüşecektir. Dolayısıyla öğrenci, İngilizceden (L2) elde ettiği bilgi ve tecrübeyi yukarıda verilmiş olan başlıklarda Almanca (L3) için rahatça kullanabilir ve bilgiler arası geçiş yapabilir.

\section{3. İngilizcenin Köprü Dil Olarak Kullanılmayacağı Yerler}

Her ne kadar Almanca ve İngilizce aynı dil ailesinin, aynı kolunda bulunuyor olsalar da farklı oldukları yerler de mevcuttur. Buna iki kardeşin sima olarak birbirine benzemesi ama huy olarak farklılık göstermesi de denilebilir. Bu duruma ilk olarak fiil çekimi örnek gösterilebilir. Almancada aynı Türkçede olduğu gibi her özne için bir çekim yapılmaktadır ama İngilizcede bu böyle değildir. Sadece üçüncü tekil kişide fiil çekimi yapılmaktadır. Ayrıca Almancada saygı anlamı taşıyan, kibarlık belirten bir özne vardır ki özne durumundaki bu "Sie" zamiri cümlenin neresinde olursa olsun büyük yazılmak zorundadır. İngilizcede böyle ekstradan bir özne yoktur. Böyle bir kibarlık İngilizcede you kelimesi ile verilmektedir. 


\begin{tabular}{|c|c|c|c|}
\hline & gehen & & go \\
\hline Ich & gehe & I & go \\
\hline $\mathrm{Du}$ & gehst & you & go \\
\hline $\mathrm{Er} / \mathrm{Sie} / \mathrm{Es}$ & geht & $\mathrm{He} / \mathrm{She} / \mathrm{It}$ & goes \\
\hline Wir & gehen & $\mathrm{We}$ & go \\
\hline Ihr & geht & You & go \\
\hline Sie (kibar)/ sie & gehen & They & go \\
\hline
\end{tabular}

Almancada, İngilizce kadar zaman (tence) bulunmamaktadır. Almancada şimdiki zaman ve geniş zaman için aynı cümle kalıbı kullanılırken, İngilizcede durum farklıdır. İngilizcede hem şimdiki zaman kalıbı hem de geniş zaman kalıbı kendi kuralları çerçevesinde kullanılır.

\section{Almanca}

Ich lese Buch.

\section{İngilizce}

I read a book. - - I am reading a book.

Almancada zaman zarfı düz bir cümlede birinci sırada ya da üçüncü sırada yer alırken İngilizcede genellikle ikinci sırada yer bulmaktadır.

\section{Almanca}

Manchmal gehe ich ins Kino.
İngilizce

I sometimes go to the Cinema.

Yukarıda da söz edildiği gibi iki dilde tanımlık vardır. Ama İngilizcede sadece bu tanımlık belirli veya belirsiz tanımlık özelliği taşır ve sadece nesnelerin önüne getirilir. Eğer cümle başı değil ise kesinlikle tanımlık ya da nesne büyük harfle yazılmaz. Ama Almancada neredeyse her ismin (özel isimler hariç) bir tanımlığı vardır. Tanımlığa sahip her kelime aynı Türkçedeki özel isim gibi cümlenin neresinde olursa olsun büyük yazılır. Almancada tanımlık cümle başı ise ilk harfi büyük yazılır. Bir de Almancanın yapısı gereği tanımlık ismin hallerinin değişimini gösterir. Ama İngilizcede böyle bir şey söz konusu değildir.

\section{Almanca}

1) Ich sehe einen Mann.

2) Ich sehe den Mann.

Birinci cümlede Almancada belirsiz “ein” tanımlığı "einen” e dönüşmüşken, İngilizcede herhangi bir değişim olmamıştır. İkinci cümlede ise belirli "der" tanımlığı "den" tanımlığına dönüşmüşken, İngilizcede yine böyle bir şey söz konusu değildir. Bu iki

\section{İngilizce}

I see a man.

I see the man. 
Almanca cümlede ismin-i hali gramer olarak gösterilmişken, İngilizcede sadece anlam olarak ismin-i hali verilmektedir. Gramer olarak böyle bir bilgi verilmemektedir.

Almancada sıfat çekimi yapılırken, sıfatın tanımlık ile isim arasında kullanılması gerekmektedir. Tanımlığın belirtili ya da belirtisiz olması, tekil ya da çoğul olması, değişip değişmemesi çok önemlidir. Ama İngilizcede böyle bir şey söz konusu değildir.

\section{Almanca}

Ich sehe den glücklichen Mann.

Ich lese ein gutes Buch.

Das ist eine schöne Frau.

\section{İngilizce}

I see the happy man.

I read a good book.

This is a beautiful woman.

Örneklerde de görüldüğü üzere, Almancada sıfat çekimi yapıldığında sıfatlar tanımlık ile isim arasında yer almaktadır ve sıfat gelmiş olduğu kelimeye göre örneklerdeki ekleri (-en, -es, -e) gramer kurallarına göre almaktadır. Tabii ki ekler sadece bu üç ek ile sinırlı değildir.

Bağlaçlar her dilde olduğu gibi bu iki kardeş dilde önemli bir yere sahiptir. İngilizcede bağlaçlar cümle düzenini bozmazken, Almanca için durum böyle değildir. Almancada kullanılan bağlaçlara göre fiilin konumu yer değiştirmektedir. Kimi zaman fiilin konumu değişmez, kimi zaman bağlaç fiili yanına çeker, kimi zamansa bağlaç fiili cümlenin en sonuna atar. Örneğin:

Ich habe Hunger und ich habe Durst.

Ich habe kein Geld, deswegen gehe ich nicht ins Kino.

Wenn ich dich sehe, bin ich froh.

\section{Sonuç}

$\mathrm{Bu}$ çalışmada ikinci yabancı dil Almanca (L3) öğretiminde, birinci yabancı dil İngilizcenin (L2) nerelerde ve nasıl köprü dil olarak kullanabileceği ortaya konulmaya çalışılmıştır. Aynı dil ailesinden ve ailenin aynı kolundan gelmeleri sebebiyle iki dilin ortak özelliklere sahip oldukları alanlarda birinci yabancı dil olan İngilizcenin (L2), ikinci yabancı dil olan Almanca öğreniminde katkısı olacağı çok açıktır.

Öğretmen ikinci yabancı dil olarak Almaca öğretimi sırasında, bu iki dilin ortak payda da buluştuğu ders materyalleri hazırlayarak ya da bu konuda üretilmiş olan materyalleri kullanarak, öğrencinin İngilizceden dilbilgisi, sözcük dağarcığı gibi bilgileri Almanca öğreniminde kullanmasını sağlar. Ders öğrenim verimini de bu doğrultuda arttırmış olur çünkü öğrenci İngilizce bilmenin rahatlı̆̆ kendini daha özgüvenli hisseder ve Almanca öğrenimine çok daha kolay uyum sağlar. 
Almancanın ikinci yabancı dil olarak öğrenilmesi dezavantaj gibi gözüküyor olabilir. Fakat İngilizcenin birinci yabancı dil olarak öğretilmesi, Almanca öğreniminde köprü dil olarak kullanılması bu dezavantajı, avantaja çevirebilir. Bunun olabilmesi için İngilizceden Almancaya olumlu transferler yapılması gerekmektedir.

İkinci yabancı dil öğrenim sürecinde öğrenci, Anadilinde (L1) olmayıp, ikinci yabancı dilde (L3) olan kavramları öğrenmede zorladığında gerekli ilgiyi göstermeyebilir. Öğretmen öğrenciyi yönlendirerek, birinci yabancı dilden (L2) örnekler vererek, öğrenciye yol göstermelidir. Çeşitli ilgi çekici örneklerle öğrenciye bunun aslında düşündüğü kadar zor olmadığı anlatılabilir. Birinci yabancı dil (L2) öğrenim sürecinde de çeşitli zorlukların yaşandığ 1 ve bunların üstesinden gelindiği belirtilebilir. İngilizce için uygulanan strateji ve ipuçlarının Almanca öğreniminde de kullanabileceği güzel bir şekilde açıklanmalı ve bu doğrultuda İngilizce köprü dil olarak kaullanılmalıdır.

\section{Kaynakça}

Akar, Ali (2005): Türk Dili Tarihi. İstanbul Ötüken Yayınları. https://www.otuken.com.tr/u/otuken/docs/turk_dili_tarihi.pdf (Son Erişim Tarihi: 16.12.2019).

Arak, Hüseyin (2006): İkinci yabancı dil olarak Almanca'nın öğrenilmesinde İngilizcenin ve karş1laştırmalı dilbilgisinin rolü. Sosyal Bilimler Enstitüsü Dergisi. 21. 205-216.

Arak, Hüseyin (2010): Almanca öğreniminde ve öğretiminde köprü dil İngilizce’den olumlu transfer örnekleri. Uluslararası Sosyal Araştırmalar Dergisi, 3. 50-60.

Arak, Hüseyin (2016): İngilizceden sonra ikinci yabancı dil olarak Almanca. International Journal of Science Studiesi, Summer II Number: 48. 15-25

Akay, Recep (2013): Neue Bemerkungen zur Untersuchung Sprachlicher Verschiedenheiten. International Journal of Social Science, 6. 1-12.

Bertocchini, Paola/ Costanzo, Edvige (1995): Autonomie de l'Apprenant, Autonomie de l'Enseignant. Methodes et Pratiques des Manuels de Langue, FDM numero special. 174-181.

Boeckman, Klaus-Börge (2010): Grundlagen des Erst-und Fremdsprachenerwerbs. Kassel-Müchen, Langenscheidt.

Holec, Henri (1990): Qu'est-ce qu’Apprendre a Apprendre. Melanges Pedagogiques. 75-87.

Karataş, Zeki (2015): Sosyal bilimlerde nitel araştırma yöntemleri. Manevi Temelli Sosyal Hizmet Araştırmaları Dergisi, 1. 62- 80.

Küzeci, Deniz (2015): Yabancı dil seçimi ve yabancı dil politikaları. Kazım Karabekir Eğitim Fakültesi Dergisi, 30. 13 - 26.

Müfredat (2013): http://bianet.org/bianet/egitim/144368-meb-ders- mufredatlarini-degistirdi. (Son Erişim Tarihi: 04.01.2020).

Porcheri, Louis (2004): L'Enseignement des Langues Entrangeres. Paris: Hachette.

Questions (2019): Erişim adresi: https://www.englishclub.com/grammar/questions.htm\#type (Son Erişim Tarihi:: 09.01.2020).

Şavlı, Fisun/ Kalafat, Semiha (2014): Yabancı dil derslerinde anadili kullanımı üzerine öğretmen ve öğrenci görüşleri. Turkish Studies, 9. 1367-1385. 
Yıldırım, Ali/ Şimşek, Hasan (2008): Sosyal Bilimlerde Nitel Araş̧ırma Yöntemleri. Ankara: Seçkin Yayıncilik.

Zengin, Dursun (2016): Her Yönüyle Modern Almanca Deutsche Grammatik. Ankara: Kurmay. 